\title{
REFLEXÕES SOBRE A MORTE, O LUTO E AS INTERVENÇÕES POSSÍVEIS
}

\author{
Amanda Rebeca Borges de Oliveira ${ }^{1}$, orcid.org/0000-0002-6498-389X \\ Eduardo Chierrito de Arruda ${ }^{2}$, orcid.org/0000-0002-2434-5359 \\ Isadora de Moraes Blogoslawski ${ }^{3}$, orcid.org/0000-0002-7132-8981 \\ Romeia Satie Sartori ${ }^{4}$, orcid.org/0000-0002-7230-7672
}

RESUMO. O presente trabalho buscou trazer reflexões sobre o significado da morte e do luto, em como se dá o processo de luto, qual é o seu tempo, o que configura um luto ser normal ou patológico, quais as intervenções possíveis e quais as necessidades de uma intervenção. Dessa forma, foi apresentado o significado da morte no ocidente através dos estudos elaborados por Phillipe Ariès (1965), observando que a morte passou, da Idade Média aos dias atuais, de um tipo de "morte familiar" para um tipo de "morte interdita". Assim, foi possível compreender como a morte se transformou ao longo dos séculos num tema tabu, em que não há mais espaço para se falar e viver a morte, tampouco acolher o enlutado, a dor do luto se tornou repugnante dentro da cultura ocidental da felicidade. Em seguida, foram apresentados conceitos teóricos a respeito do processo do luto através de autores clássicos como Sigmund Freud (1917) com o artigo "Luto e Melancolia" e Elisabeth Kübler-Ross (1969) com o livro "Sobre a Morte e o Morrer". Foram apresentados também autores de artigos contemporâneos como Freitas (2017) que estudam o luto sob uma perspectiva fenomenológica-existencial, onde o luto é compreendido não mais como um processo linear que se supera, como apresentou Freud e Kübler-Ross, e sim algo que possui uma continuidade em que é preciso construir novos significados para a vida futura com a existência ausente de quem morreu. Foram então apresentadas intervenções possíveis dentro de algumas teorias, entendendo que autores como Freud (1917) entende o luto como processo natural e que é superado após um determinado tempo, e outros autores, como Aciole e Bergamo (2019) e Andrade, Barbieri e Mishima-Gomes (2017) irão compreender a intervenção como uma possibilidade importante que produz alívio para o enlutado uma vez que não há muitos espaços para se viver o luto e ressignificá-lo dentro da nossa cultura. Por fim, trouxemos à reflexão a necessidade de espaços de acolhimento e escuta para pessoas e famílias enlutadas através de políticas públicas e também a necessidade de romper as barreiras em relação aos temas da morte, promovendo mais espaços de discussão em que falar da morte é dar voz à dor humana e a liberdade a uma vida digna de ser vivida.

\footnotetext{
${ }^{1}$ rebecaamanda926@gmail.com, discente da UniFCV

${ }^{2}$ prof_chierrito@unifcv.edu.br; docente da UniFCV

3 isadoramb@outlook.com; discente da UniFCV

${ }^{4}$ romeia_satie@yahoo.com.br, discente da UniFCV
} 
[v.1, n.1] Jan./Jun.2020

Palavras-chave: luto, morte, psicologia, intervenções

\title{
REFLECTIONS ON DEATH, MOURNING AND POSSIBLE INTERVENTIONS
}

\begin{abstract}
The present work sought to bring reflections on the meaning of death and mourning, on how is the process of mourning, what is its time, what constitutes a mourning being normal or pathological, what are the possible interventions and what are the needs of a intervention. In this way, the meaning of death in the West was presented through studies prepared by Phillipe Ariès (1965), noting that death has passed, from the Middle Ages to the present days, from a type of "family death" to a type of "prohibited death ". Thus, it was possible to understand how death has become a taboo theme over the centuries, in which there is no more space to speak and live death, nor to welcome the mourner, the pain of mourning has become disgusting within the Western culture of happiness. Then, theoretical concepts about the mourning process were presented through classic authors such as Sigmund Freud (1917) with the article "Mourning and Melancholia" and Elisabeth Kübler-Ross (1969) with the book "On Death and Dying". Contemporary authors such as Freitas (2017) who study mourning from a phenomenological-existential perspective were also presented, where mourning is no longer understood as a linear process that overcomes itself, as presented by Freud and Kübler-Ross, but something that it has a continuity in which it is necessary to build new meanings for the future life with the absence of the one who died. Possible interventions were then presented within some theories, understanding that authors like Freud (1917) understand mourning as a natural process and that it is overcome after a certain time, and other authors, such as Aciole and Bergamo (2019) and Andrade, Barbieri and MishimaGomes (2017) will understand the intervention as an important possibility that produces relief for the mourner since there are not many spaces to experience mourning and resignify it within our culture. Finally, we brought to the reflection the need for welcoming and listening spaces for bereaved people and families through public policies and also the need to break barriers in relation to the themes of death, promoting more spaces for discussion in which to speak about death is to give voice to human pain and freedom to a life worth living.
\end{abstract}

Keywords: mourning, death, psychology, interventions.

\section{INTRODUÇÃO}

Todos nós em algum momento de nossas vidas já vivenciamos ou vivenciaremos o luto. $\mathrm{O}$ desencadeamento do processo de luto pode se dar através de uma reação à perda de familiares, amigos, colegas de trabalho, animais de estimação, ou seja, de forma geral trata-se da perda por morte de pessoas queridas e próximas a pessoa que vivencia o luto. 
[v.1, n.1] Jan./Jun.2020

Há ainda autores que também expandiram a compreensão do luto em outros processos que não necessariamente envolveriam a perda por morte de alguém e sim as perdas simbólicas que ocorreriam ao longo da vida do próprio sujeito, como a passagem da infância para a vida adulta, a saída da casa dos pais, uma mudança de cidade, o distanciamento e separação de velhos amigos, perda de velhas crenças, etc (TEIXEIRA, 2007).

Portanto, vida e morte são processos naturais e presentes em nosso cotidiano, mas por que a morte de pessoas que nós amamos seria causa de tanto sofrimento? O luto seria sempre normal e igual para todos? Quando este sofrimento, que é característico no processo do luto, cessaria? Qual seria o tempo do luto? Quando se tornaria necessário uma intervenção no processo do luto e quais seriam as possíveis intervenções neste caso?

O luto tem sido objeto de estudo de muitos pesquisadores e sob o olhar de diferentes abordagens psicológicas que propuseram compreensões distintas quanto à forma de intervir no luto quando necessário. Essa compreensão distinta na forma em se lidar com o luto estaria relacionada com a perspectiva da abordagem de como seria esse processo psíquico do trabalho de luto.

Freud, em seu artigo Luto e Melancolia (1917), discorreu sobre o luto como "uma reação a perda de uma pessoa querida ou de uma abstração que esteja no lugar dela, como a pátria, liberdade, ideal, etc". Ele ainda considerou o luto como algo não patológico apesar de entender que haveria um processo de sofrimento profundo pela perda da pessoa amada, gerando um desânimo doloroso, a perda de interesse pelo mundo externo, a perda da capacidade de amar ou substituir o objeto perdido e o afastamento de toda atividade que não tivesse relação com a pessoa amada. Freud explicou que haveria um investimento muito forte da energia psíquica em relação ao objeto perdido e que só através do trabalho de luto, que se daria dentro de um determinado tempo, a pessoa enlutada iria deixar de investir essa energia psíquica na pessoa que partiu e começaria a investir essa energia em outro objeto de amor. Desta forma, o trabalho de luto estaria finalizado.

Assim, Freud compreendeu o luto como um processo natural, normal e não patológico, contudo, entende-se que cada pessoa passará pelo luto de forma distinta de acordo com inúmeros fatores como sua história de vida, a sociedade em que esta pessoa faz parte, seus marcadores sociais, etc. Ou seja, cada pessoa irá vivenciar o luto de forma 
[v.1, n.1] Jan./Jun.2020

muito particular dentro da sua realidade podendo o luto se realizar de forma "normal" ou não.

Segundo Freitas (2018), ocorreram mudanças na compreensão do luto no DSM-5 (Manual de Diagnóstico e Estatístico de Transtornos Mentais, quinta edição), onde foi realizada uma diferenciação entre o que seria o "luto normal" e o luto com caráter "depressivo" ou "complicado". De acordo com o DSM-5, o luto complicado seria um luto que tem seus sintomas presentes se estendendo por um ano em adultos e seis meses em crianças. Porém, embora tenha ocorrido essa diferenciação entre luto normal e complicado, Freitas considerou o luto dentro de um aspecto fronteiriço entre aquilo que se poderia considerar normal e patológico.

Freitas (2018) pontuou o processo do luto como "uma vivência imprevisível, inexplicável e desconexa dos demais estágios vivenciados anteriormente" e ainda refletiu o luto como uma experiência não somente intrapsíquica como também social, devido à "perda de papéis" que se vivencia quando se perde alguém amado. Um filho que perde o pai, não só perde o pai e as possibilidades de convívio com o pai no futuro, mas perde também a sua posição de filho. Assim a autora, dentro de uma abordagem fenomenológica-existencial propôs uma tarefa da psicoterapia no processo de luto, de mobilizar recursos narrativos para a construção de um sentido a perda ajustada às necessidades de cada indivíduo enlutado.

Portanto o presente trabalho buscou conceitos e interpretações de algumas abordagens teóricas como a psicanálise e a fenomenológica-existencial para entender o luto, seu processo psíquico e social e as possíveis formas de auxiliar, apoiar e fortalecer o sujeito enlutado para o enfrentamento do luto, tão delicado, singular e de sofrimento tão intensificado.

\section{METODOLOGIA}

A construção do presente artigo foi de caráter de estudo qualitativo que se realizou através da revisão narrativa. Os artigos de revisão fazem parte de uma categoria de artigo científico, em que a pesquisa se utiliza de fontes de informações bibliográficas ou eletrônicas a fim de aproveitar os resultados de outros autores para se fundamentar teoricamente um determinado objetivo. Os artigos de revisão podem ser divididos em duas categorias: artigos de revisão narrativa e artigos de revisão sistemática. Os artigos 
[v.1, n.1] Jan./Jun.2020

de revisão narrativa são publicações amplas, que descrevem e discutem o desenvolvimento de um determinado tema sob o ponto de vista teórico ou contextual (Rother, 2007).

A revisão narrativa é considerada a revisão tradicional e exploratória, onde não há a definição de critérios explícitos e a seleção dos artigos a serem utilizados no trabalho segue o viés do autor não sendo necessário se esgotar as fontes sobre determinado assunto (Cordeiro et al, 2007).

A busca de informações para a elaboração deste artigo foi feita através da base de dados LILACS, PePSIC e SciELO, além de referências em livros que julgamos relevantes para o desenvolvimento do tema. Foi adotado o critério de inclusão somente artigos indexados, delimitando o tempo para os artigos que foram publicados nos últimos cinco anos. Foram critérios de exclusão os artigos publicados em outras línguas como língua inglesa, espanhola, etc, portanto foram escolhidos os artigos preferencialmente publicados em língua portuguesa.

Através de pesquisas nas bases de dados LILACS, PePSIC e SciELO, buscando como palavras-chaves de forma combinada com a palavra "luto", tais como "superação", "história", "saúde", "saúde mental”, "intervenções", "luto normal”, "luto patológico", "psicanálise", "fenomenologia" e "psicodrama", foram encontrados 183 artigos. Foram então desconsiderados os artigos repetidos e também aqueles que não respondiam ao problema de pesquisa.

\section{RESULTADOS E DISCUSSÃO}

Para respondermos ao nosso problema de pesquisa e chegarmos à ideia de como se caracteriza o trabalho de luto, as reações afetivas envolvidas e as possíveis intervenções durante este processo é necessário entender primeiramente o significado da morte e do morrer dentro de uma perspectiva histórica.

Phillippe Ariès realizou pesquisas durante 15 anos sobre as atitudes diante da morte nas culturas ocidentais cristãs e as reuniu no livro "História da Morte no Ocidente" lançado em 1975. Através de interpretações de obras de artes, literatura, documentos em igrejas, testamentos, túmulos e cemitérios, Ariès conseguiu estabelecer as diferenças existentes das atitudes do homem ocidental diante da morte ao longo dos séculos. 
[v.1, n.1] Jan./Jun.2020

Entre a idade média até o século XIX, Ariès (1975) denominou a morte como uma "morte domada", ou seja, não se morria sem saber que ia se morrer. A morte eminente não era escondida nem da pessoa em processo de morte nem de seus amigos e familiares. As pessoas se reuniam na casa do doente para lhe prestar as últimas homenagens, se despedir, pedir desculpas ou até mesmo se comprometer a continuar algo inacabado. Neste período em que a morte era domada, três importantes características se destacavam: a morte era esperada no leito, a morte era uma cerimônia pública organizada pelo próprio moribundo (onde participam parentes, amigos, vizinhos e também as crianças) e existia uma simplicidade em que os ritos de morte eram aceitos sem um caráter dramático ou gestos de emoções excessivas. Assim se morreu por vários séculos.

A partir da segunda metade do século XIX, Ariès (1975) percebeu que as pessoas que cercam o moribundo tendem a poupá-lo e ocultar a gravidade de seu estado. E esse sentimento vai sendo substituído, não mais com o propósito de poupar a pessoa que está morrendo, e sim "poupar a sociedade e as pessoas que o cercam, da perturbação e as emoções excessivamente fortes, insuportáveis causadas pela fealdade da agonia, já que se torna inaceitável a simples morte em plena vida feliz". A partir de então se entende que a vida é sempre feliz ou assim deveria ser e se a dor do luto antes causava pena agora ela se torna repugnante. Já não se morre mais em casa junto aos familiares e pessoas amadas, mas sozinho, num hospital. Portanto a morte e, consequentemente, o luto, vão se tornando "tabus" dentro de uma sociedade que não aceita os rompimentos, as perdas, os sentimentos de tristeza, e então a morte passa a tornar-se uma "morte interdita", nomeada assim pelo próprio autor. "A morte, no passado tão presente e familiar, vai se apagar e desaparecer, tornando-se vergonhosa e objeto de interdição".

A perda dos ritos simbólicos diante da morte, que traziam o fenômeno para um lugar familiar na vida humana, fez o homem perder o direito à própria morte. Tirou-lhe $\mathrm{o}$ direito de saber que está morrendo, de escolher onde vai morrer e a autonomia de viver da forma que lhe convém o pouco tempo que lhe resta. A morte interdita tira também o direito dos familiares e amigos de se despedir, agradecer, desculpar-se, ou qualquer coisa que gostariam de vivenciar com a pessoa antes de sua partida.

A morte interdita faz com que a morte apareça de forma inesperada na vida das pessoas, como uma intrusa, gerando fortes reações afetivas de angústia, desamparo e tristeza. Evita-se falar sobre o tema da morte, mesmo aqueles que trabalham e convivem 
[v.1, n.1] Jan./Jun.2020

com a morte todos os dias. Elisabeth Kübler-Ross (1969), em seu livro Sobre a Morte e o Morrer, aponta através de suas vivências como psiquiatra, a dificuldade de seus colegas médicos e equipe de enfermagem em lidar com o tema da morte. Os profissionais, além de apresentarem dificuldades em comunicar-se com os pacientes sobre o tema, evitam a morte de toda a forma através de intervenções desnecessárias que fazem prolongar o processo de morte, causando mais sofrimento ao paciente e aos seus familiares.

Kübler-Ross (1969), através de sua experiência e pesquisa com pacientes em processo de morte, elaborou cinco fases presentes no processo de morrer que podem ser expandidas também para a compreensão de fases do luto. As fases em ordem sequencial seriam: "negação e isolamento", em que a pessoa nega o adoecimento e a morte eminente, "raiva", em que a pessoa se questiona do "por que ela?" e se revolta contra tudo e todos, "barganha", em que o sujeito tenta negociar algo já que está prestes a morrer, “depressão", em que o sujeito irá vivenciar o processo de uma grande perda e irá compreender sobre o fim eminente e a perda dos objetos amados e por último a fase da "aceitação" em que o sujeito aceita a própria morte.

A "barganha" para o processo de luto seria como se o enlutado se apegasse a crenças e simbolismos, de ordem religiosa ou não, num processo de ainda tentar manter o ser amado por perto, mesmo que só em seu imaginário. Dessa forma, Kübler-Ross nos traz essa ideia de fases a serem atravessadas na elaboração do luto, que terminará com a aceitação da morte de quem partiu. A autora apresenta essas fases como processos psíquicos que não demandam intervenções profissionais para que ocorram, embora nem todas as pessoas vivenciem todas as fases podendo se fixar em alguma das fases sem chegar à "aceitação".

Apesar de serem fases que se dão naturalmente, Kübler-Ross nos traz a reflexão sobre os benefícios de uma escuta atenta e o acolhimento para com as pessoas em processo de morte, permitindo que elas possam expressar suas angústias, raivas, medos, dando-as voz e uma autonomia sobre suas vidas, apesar de todas as limitações impostas pela gravidade de suas doenças.

Freud (1917) também estabelece o trabalho de luto como um processo psíquico natural que se supera depois de um determinado tempo. O luto, para ele, é compreendido como uma reação à perda de uma pessoa querida, que produz um "estado de ânimo doloroso, a perda de interesse pelo mundo externo, a perda da capacidade de escolher um 
[v.1, n.1] Jan./Jun.2020

novo objeto de amor e o afastamento de toda e qualquer atividade que não tenha relação com a pessoa amada".

O trabalho de luto para Freud (1917) deve ocorrer através do que ele denominou "teste de realidade", no qual o indivíduo enlutado irá constatar que o objeto amado não existe mais e gradativamente irá deslocar a energia libidinal investida no objeto para si mesmo ou para outrem. Contudo esse deslocamento de energia se dará com grande dispêndio de tempo e de energia de investimento. As lembranças e expectativas pelas quais a libido se ligava ao objeto vão sendo focalizadas e superinvestidas e então ocorre o desligamento da libido. A execução desse processo se dá de forma dolorosa, e uma vez concluído o trabalho de luto, o ego se torna livre e desinibido.

Em relação à dor do luto, Medeiros (2019) compreende, através da perspectiva freudiana, que a libido apega-se ao objeto perdido com maior intensidade, reforçando o investimento da energia libidinal para com o objeto perdido. Assim no processo de luto, que consiste em desligar-se desse objeto, há um alto investimento na representação do objeto, que faz com que esse processo de desligamento ocorra de forma penosa e dolorosa.

Ao se compreender que o trabalho de luto ocorre de forma dolorosa, é necessário refletir se esse processo não tem se tornado ainda mais doloroso na contemporaneidade, uma vez que os temas relacionados à morte são evitados. Atualmente em nossa sociedade ocidental, em que existem muitos espaços para compartilhar os sucessos e as felicidades e poucos espaços para compartilhar as tristezas e angústias, que são vistas como repulsivas, o enlutado acaba por ter que viver com seu sofrimento invisível em um não lugar. Sem um espaço para compartilhar suas dores, pode-se deduzir que o trabalho de luto se tornará mais doloroso, longo e difícil.

Para Aciole e Bergamo (2019), "mesmo quando o processo de luto é considerado normal, não significa que não exista o sofrimento e a necessidade de adaptação à nova estrutura familiar". Logo os autores levantam a importância da existência de lugares, espaços, em que as pessoas enlutadas possam se expressar livremente, compartilhar suas dores e experiências na busca de soluções para os problemas enfrentados.

Aciole e Bergamo (2019) refletem a importância do acolhimento à família enlutada através da observação e pesquisa com grupo terapêutico para pessoas enlutadas, organizado por um hospital de forma gratuita. Eles observaram que além dos enlutados compartilharem sentimentos como "perda de sentido da vida", "falta de motivação para 
[v.1, n.1] Jan./Jun.2020

atividades rotineiras e sociais", um novo fator apareceu como intensificador do sofrimento de algumas pessoas, a vulnerabilidade social. Brigas familiares e problemas financeiros apareceram como resultados da morte e proporcionaram uma intensificação da dor do luto.

Portanto é necessário entender o sofrimento do luto como também um sofrimento que é agravado pelos fatores sociais e econômicos, já que o enlutado pode estar vivenciando, além de todas as perdas já expostas até agora, uma situação de vulnerabilidade em sua família e a perda de uma autonomia financeira. As pessoas que participaram desse grupo terapêutico disseram ainda que este processo de acolhimento foi fundamental para que elas pudessem se sentir mais fortes, compreendidas e assim elaborar tudo o que estavam vivenciando naquele momento.

Há autores, como Freitas (2017), que irão compreender o trabalho de luto não mais enquanto etapa e fases, como Kübler-Ross apresentou, ou como um processo linear e uma experiência que se supera, como entendido por Freud. A autora também refuta a ideia de se estabelecer novos vínculos para a superação do luto, porque embora a pessoa amada não exista mais em sua forma física, ela continua a existir simbolicamente através das memórias compartilhadas e as reações afetivas a essas memórias.

Seguindo uma abordagem fenomenológica-existencial, Freitas (2017), compreende o luto para além de uma experiência intrapsíquica, portanto, como uma experiência também social. Segundo a autora "o luto é um fenômeno que tem início com a abrupta supressão do outro enquanto corporeidade”. É uma ruptura das existências no espaço e tempo entre dois indivíduos, que produz angústia e impotência diante do desaparecimento do outro e da interrupção da história em comum. A autora traz a reflexão sobre a existência humana, que se dá através do "entrelaçamento sensível com o outro". Portanto a perda da pessoa amada poderia ser entendida como "perder um mundo, uma profundidade e perspectiva".

Na contramão das intervenções tradicionais, Freitas (2017) propõe que o trabalho do psicólogo seria "abrir a possibilidade de manutenção do morto enquanto sentido na vida do enlutado". A tarefa do luto seria promover a existência do enlutado mesmo com a ausência, já que não é mais possível voltar à vida anterior, e fazê-lo "encontrar novos sentidos e um modo de ser com aquele que morreu, uma ressignificação entre o morto e o enlutado". 
[v.1, n.1] Jan./Jun.2020

Para Michel e Freitas (2019) ressignificar o luto significa "respeitar a nova condição a que o enlutado é lançado, em que novas possibilidades de ser se apresentam e são evidenciadas justamente pela ausência-presente daquele que morreu". Os autores afirmam que o processo clínico deve buscar a abertura de novas possibilidades para o sercom, mantendo a presença de quem se perdeu como ausência, incorporada no modo de ser de quem ficou.

Portanto, através de uma perspectiva fenomenológica-existencial, os autores compreendem a elaboração do luto não mais como uma substituição do ser amado, nem como etapas a serem superadas, nem como uma volta à vida que era antes, mas sim como a possibilidade de seguir em frente com a ausência, criando novos significados para a vida futura com o ser amado dentro de uma existência simbólica.

Seguindo uma análise semelhante em relação ao trabalho de luto, Andrade, Barbieri e Mishima-Gomes (2017) propõem que são partes do trabalho de luto as tarefas estabelecidas por Cohen, Mannarino, \& Knudsen (2004) como: a aceitação da realidade da morte, a experimentação da dor por completo, a procurar para se ajustar a nova vida, a integração dos aspectos do ente querido à própria identidade e o encontro do significado na perda para se iniciar novas relações. Andrade, Barbieri e Mishima-Gomes (2017) entendem o luto como algo individual, particular e relatam a importância de programas que ofereçam auxílio profissional para que essa pessoa se sinta amparada e compreendida.

Pensar a necessidade de um auxílio profissional para o trabalho de luto é bastante complexo. Como já foi mencionado, alguns autores irão entender que não é necessário como Freud (1917), já que o luto é um processo psíquico normal, porém outros autores irão visualizar o auxílio profissional como um processo de humanização do cuidado para com o indivíduo enlutado, como Aciole e Bergamo (2019), independente de se tratar de uma condição normal ou não. Mas afinal quais seriam os critérios que estabelecem um luto normal ou um luto complicado?

De acordo com o DSM-5 o luto normal seria delimitado no prazo de 12 meses para adultos e 6 meses para crianças e a partir desse período, se a pessoa continuasse a apresentar os sintomas persistentes de um luto, ela seria diagnosticada com o Transtorno do Luto Complexo e Persistente, transtorno este que o próprio DSM-5 considera a necessidade de maiores estudos (Michel e Freitas, 2019). 
[v.1, n.1] Jan./Jun.2020

Michel e Freitas (2019) refutam a ideia de se caracterizar o luto através de um tempo cronológico e pontuam o processo do luto como uma experiência sempre inacabada, como se fossem ondas, em que a dor do luto tende a ser revivida, embora com menor intensidade e frequência, nas datas comemorativas e nas lembranças de momentos significativos com a pessoa amada.

Para além de relacionar o luto complicado com um período de luto acima de 12 meses, Michel e Freitas (2019), através da leitura de Tatossian, nos sugerem pensar sobre essa diferenciação de normal e complicado, através da díade liberdade e não liberdade. Ou seja, pensar como complicado ou patológico quando o sujeito perde a sua autonomia frente aos sofrimentos estabelecidos pelo luto. Se a autonomia do enlutado encontra-se em alguma medida preservada não há que se falar em patologia.

Mesmo assim, isso não significa que este sujeito, embora autônomo de si, não precise de ajuda profissional, uma vez que já foi demonstrado que o tema da morte e do luto não tem encontrado espaços de discussão em nossa sociedade contemporânea. Em nossa cultura ocidental, ao ignorarmos o tema da morte, o luto e o sofrimento, não abrimos ao outro um espaço de diálogo, de conforto e compreensão, e dessa forma, não possibilitamos ou ainda, dificultamos a experiência de um luto normal. Refletir sobre o luto é refletir sobre a cultura em que estamos inseridos e qual o impacto dessa cultura nas subjetividades das pessoas e consequentemente nas experiências de seus lutos.

Pontes e Souza (2016) trazem a reflexão de um problema de nossa cultura na elaboração do luto de pais que perderam filhos recém-nascidos. Esses pais muitas vezes tendem a esconder seus sentimentos e são impossibilitados de realizar os processos ritualísticos de simbolização da perda por questões sociais e culturais, impedindo a transformação da morte do bebê em um significado de perda de um filho. Assim os pais sofrem calados, passando por um processo de luto invisível e doloroso, já que a cultura não abre espaços para essa dor seja assistida.

É importante entender que ao longo dos séculos na sociedade ocidental, os ritos e as simbolizações foram sendo desvalorizados e esquecidos. Ritos estes que facilitavam a pessoa a atravessar o luto, uma vez que a cerimônia da morte era organizada como uma cerimônia pública, em que mesmo pessoas que não conheciam o morto, participavam dessas cerimônias e cortejos (Ariès, 1975). É de se esperar que num ambiente assim, os 
[v.1, n.1] Jan./Jun.2020

enlutados percebam o seu sofrimento como um sofrimento "autorizado" e compartilhado com todos ali envolvidos, que podem se apoiar, acolher-se e seguir em sua nova condição.

Os ritos e cerimônias podem ser considerados instrumentos facilitadores do processo de luto, quando os mesmos possibilitam: que as pessoas se expressem de forma livre e espontânea, sejam acolhidas e respeitadas, elaborem e deem significado para suas existências diante da morte e da falta do ente querido.

Farrez (2019), através de sua experiência com atendimento a pessoas enlutadas em Singapura, propôs uma ferramenta que ele denominou "Certidão de Vida", como uma espécie de rito facilitador para as terapias de luto. Ele sentiu a necessidade de criar essa ferramenta ao se deparar com a forma com que seus clientes eram impactados diante da perda da pessoa amada, com dificuldades em ressignificar suas lembranças e lidar com assuntos que ficaram pendentes.

A ferramenta de "Certidão de Vida" é uma proposta em que o autor busca tornar pública a história de vida de quem morreu, proporcionando reflexões de como essa pessoa influenciou e foi influenciada pela pessoa enlutada. Nessa ferramenta, o enlutado tem a possibilidade de apresentar fotos, músicas, lugares que a pessoa mais frequentava, frases que a pessoa dizia, o que era mais admirável nessa pessoa, valores e lições de vida aprendidos, enfim, uma ferramenta construída através de muitas lembranças e significados para o enlutado. Essa ferramenta permite ao enlutado elaborar e organizar todas as narrativas envolvendo a sua perda, podendo ressignificar suas memórias com a pessoa amada através de uma nova história que se torna pública.

Farrez (2019) também apresenta a necessidade de olhar o enlutado para além da cultura, já que "as crenças dominantes podem ser opressivas por levar as pessoas a obedecer a ideias "normativas" do luto que podem não se encaixar com seus próprios pontos de vista". Ou seja, é necessário olhar para a subjetividade do sujeito que pode estar em consonância ou não com esta cultura, uma vez que "a relação de cada pessoa com a cultura e a religião é única diante da sua própria compreensão de mundo".

Portanto, a influência da cultura diante dos ritos de morte pode tanto ir de encontro como um processo facilitador de elaboração do luto como também pode ser desastrosa para as pessoas. É necessário que o profissional de saúde, ao trabalhar com pessoas enlutadas, esteja sempre sensível e atento às suas subjetividades, à história de vida do indivíduo, à representação da pessoa amada na vida do sujeito, à sua religião e crenças, e 
[v.1, n.1] Jan./Jun.2020

também aos marcadores sociais envolvidos que podem ser atravessados por raça, gênero, sexualidade etc. Ou seja, para compreender o enlutado e promover sua saúde e autonomia diante do sofrimento, é urgente pensar nos múltiplos fatores que envolvem sua forma de ser e existir no mundo, pois encarar esses fatores e reconhecê-los é fazer submergir outras questões potencializadoras das dores humanas.

Outra possibilidade para a elaboração do luto, ainda nessa perspectiva de se estabelecer novas significações para o enlutado, é a utilização do psicodrama. Segundo Strauch (2017), a ação psicodramática conduz o sujeito à própria realidade, contribuindo para sua maior conscientização e mobilização afetiva. Na encenação psicodramática é objetivado a representação em busca de uma solução, que no processo de luto, pode ser oportunizar uma despedida, externar algo reprimido, desengasgar ou ressignificar os papéis perdidos.

Portanto até aqui foi possível refletir sobre muitas intervenções que são possíveis para auxiliar nesse processo tão doloroso na vida dos sujeitos. Essas intervenções obviamente não se tratam de intervenções obrigatórias já que se espera que o trabalho do luto ocorra de forma natural. Contudo, uma intervenção profissional, percebendo que o tema morte ainda é interdito na sociedade contemporânea ocidental, pode ser um grande alívio na vida dessas pessoas que vivem suas dores e tristezas de forma privada, contando muitas vezes com pouco ou nenhum apoio familiar. Essas intervenções devem ocorrer sempre buscando o respeito à subjetividade, a promoção da saúde e a autonomia do sujeito, entendendo que não há um tipo de luto e sim lutos, e que cada ser humano é singular na sua forma de expressar e existir em sua condição de enlutado.

Mas, além de pensar nas intervenções possíveis, é necessário pensar também como elas podem chegar a quem precisa, afinal nem todas as pessoas podem pagar por terapias - sejam elas individuais ou em grupos. É necessário pensar em políticas públicas que possam acolher o sujeito ou a família enlutada. E, por fim, os temas da morte e do luto devem começar a atravessar as barreiras da condição de interdição e estar presente em mais espaços de discussão, sendo estritamente necessário falar de morte quando se fala também em promoção de saúde e vida.

A morte está aí, quer a gente queira, quer não. Todos vamos morrer.

\section{CONSIDERAÇÕES FINAIS}


[v.1, n.1] Jan./Jun.2020

Através deste trabalho foi possível analisar a mudança da sociedade ocidental frente aos fenômenos da morte e do morrer. A morte entendida na idade média até o século XIX como um fenômeno familiar, em que sabe-se que vai morrer e os ritos e cerimonias são organizados pelo próprio moribundo, passa a partir da metade do século XIX a ser um fenômeno indigno, evitado, velado, interdito em que a sociedade repugna seus efeitos, sofrimentos, dores e angústias (Ariès, 1965).

A morte interdita nos leva a crer que acaba por tornar a elaboração do luto mais complicada do que o esperado, produzindo mais dor, já que não há espaços de acolhimentos para os seus efeitos e o sujeito enlutado. Também nos faz refletir a importância de intervenções profissionais, não para medicalizar o sujeito enlutado, mas para servir como um continente para essas dores, aliviando as dores do luto através de um movimento de tornar visível o sofrimento, o enlutado, a pessoa amada perdida e sua morte.

É preciso refletir as possibilidades de tirar o tema da morte desse lugar assombroso que ele ocupa, para que as pessoas possam ter o direito de viver a própria morte, saber que está morrendo e se preparar para o que está posto e é inevitável. É preciso devolver aos familiares e amigos, o luto público, em que as dores podem ser compartilhadas e que não há problema em estar triste e desanimado pelo tempo que for necessário. É preciso humanizar a vida humana, que não é somente constituída de alegrias, ganhos e sucessos, mas também de muitas tristezas, perdas e fracassos.

Kubler-Ross (1969) entende o luto através de fases, Freud (1917) através de um processo linear que se finaliza com o rompimento da energia investida na pessoa amada. Os dois acreditam que após determinado tempo o luto estará finalizado. Michel e Freitas (2019) acreditam que o luto se dá em ondas, provocando sofrimento sempre que houver lembranças e datas comemorativas que façam lembrar a pessoa que morreu. Para eles não há que se falar em superação do luto ou a volta a vida anterior, então o profissional da psicologia deve auxiliar o enlutado a criar e encontrar novos significados para sua existência futura através da presença simbólica do ente querido.

Independente das bases teóricas para a caracterização do processo de luto e os tipos possíveis de intervenções, é necessário refletir a necessidade de possibilitar o acesso público e gratuito de acolhimento profissional para todas as pessoas enlutadas que assim o desejarem. Como foi visto, o sofrimento no processo de luto pode ser agravado por 
[v.1, n.1] Jan./Jun.2020

múltiplos fatores que atravessam a vida das pessoas, como brigas familiares, problemas financeiros, a cultura e também os marcadores sociais como raça, gênero e sexualidade. Esses marcadores merecem ser explorados em estudos posteriores pois são prováveis de relação com o agravamento do sofrimento e vulnerabilidade na elaboração do luto.

Portanto, olhar para o enlutado é pensar em um indivíduo singular atravessado por múltiplos fatores que o constituem. Cada dor é uma dor, cada luto é um luto. A mesma pessoa pode viver lutos de formas muito diferenciadas. O profissional que auxilia, independentemente de seu método ou experiência prática, deve olhar o sujeito de forma particular, como aquele que traz consigo sempre alguma novidade para a teoria, para então ser capaz de promover a sua liberdade e a autonomia, produzindo juntos um mundo com novos significados, e assim emancipar o sujeito para a vida diante da morte.

\section{REFERÊNCIAS}

Ariès, P. (1975). A história da Morte no Ocidente: da Idade Média aos Nossos Dias. Rio de Janeiro: Nova Fronteira.

Aciole, G. G., \& Bergamo, D. C. (2019). Cuidado à família enlutada: uma ação pública necessária. Saúde debate, 43 (122), 805-818.

Andrade, M. L., Mishima-Gomes, F. K. T., \& Barbieri, V. (2017). Recriando a vida: o luto das mães e a experiência materna. Psicol. teor. prat, 19 (1), 21-32.

Cordeiro, A. M., Guimarães, C. A., Oliveira, G. M., \& Renteria J. M. (2007). Revisão sistemática: uma revisão narrativa. Rev. Col. Bras. Cir., 34 (6), 428-431.

Fareez, M. (2019). A $\square$ Certidão de Vida $\square$ : Uma ferramenta para trabalhar o luto em Singapura. Nova perspect. sist., 28 (63), 5-20.

Freitas, J. L. (2018). Luto, pathos e clínica: uma leitura fenomenológica. Psicol. USP, 29 (1), 50-57.

Freud, S. (1917). Luto e Melancolia. São Paulo: Cosac Naify.

Kübler-Ross, E. (1969). Sobre a Morte e o Morrer. São Paulo: WMF Martins Fontes.

Maesso, M. C. (2017). O tempo do luto e o discurso do Outro. Ágora, 20 (2), 337355. 
[v.1, n.1] Jan./Jun.2020

Medeiros, C., \& Fortes, I. (2019). A dor do luto: perspectivas psicanalíticas. Trivium, 11 (2), 222-234.

Michel, L. H. F., \& Freitas, J. L. (2019). A clínica do luto e seus critérios diagnósticos: possíveis contribuições de Tatossian. Psicol. USP, 30.

Rother, E. T. (2007). Revisão sistemática X revisão narrativa. Acta paul. enferm., $20(2), 5-6$.

Silva, M. K., \& Ulhoa, A. P. (2015). A Construção do Caso Clínico na Prática Hospitalar: algumas Reflexões Sobre Luto e Toxicomania. Psicol. cienc. prof., 35 (2), 503-514.

Souza, A. M. S., Pontes, S. A. (2016). As diversas faces da perda: o luto para a psicanálise. Analytica, São João del Rei, 5 (9), 69-85.

Strauch, V. R. F. (2017). Ressignificação da morte na abordagem psicodramática: perdas e ganhos no luto. Rev. bras. psicodrama, 25 (1), 59-67.

Teixeira, M. A. R. (2007). A concepção freudiana de melancolia: elementos para uma metapsicologia dos estados da mente melancólicos. Dissertação de Mestrado, Universidade Estadual Paulista, Faculdade de Ciências e Letras de Assis, Assis, SP, Brasil. 